\title{
Contact dermatitis in students practicing sports: incidence of rubber sensitisation
}

\author{
M T Ventura, M Dagnello, M G Matino, R Di Corato, G Giuliano, A Tursi
}

\begin{abstract}
Background-Over the last few years, changes in cutaneous homoeostasis resulting from sports activities have been reported. In particular, alterations in sweating mechanisms, the hydrolipid barrier, and surface bacterial flora, together with exposure to atmospheric conditions and the need to use medicaments, detergents, and other topical substances, predispose subjects to allergic contact dermatitis.

Objective-To evaluate the incidence of allergic contact dermatitis in a group of young people practising sports activities. Methods-Patch tests were performed to confirm the diagnosis of irritant or allergic dermatitis; in addition, the radioallergoabsorbent test (RAST) to latex was evaluated in the group studied.

Results-Allergic contact dermatitis caused by thiourams $(23.3 \%)$ and mercaptobenzothiazole $(20.9 \%)$ was prevalent. Other haptens, such as benzocaine and nickel, which are contained in clothing, equipment, topical medicaments, and creams used for massage, were also allergenic. In two cases, RAST positivity to latex was registered.

Conclusions-The results suggest that close contact with sports equipment may increase the incidence of allergic contact dermatitis. Students practising certain sports may have "professional" allergic contact dermatitis to additives used in the production of rubber.

(Br F Sports Med 2001;35:100-102)
\end{abstract}

Keywords: skin; allergic contact dermatitis; latex; patch test; equipment; thiourams

Department of Internal Medicine, Immunology and Infectious Disease, University of Bari

Medical School,

Policlinico, Bari, Italy

M T Ventura

M Dagnello

M G Matino

R Di Corato

G Giuliano

A Tursi

Correspondence to:

Dr Ventura, Department of Internal Medicine,

Immunology and Infectious

Disease, Policlinico di Bari,

Piazza G Cesare, 70124 Bari, Italy

mt.ventura@allergy.uniba.it

Accepted 30 October 2000 worn by racing drivers modifies the defensive capacity of the skin, altering the hydrolipid barrier and surface microbial flora. ${ }^{1}$
At the same time, exposure to sun and other atmospheric conditions triggers a series of reactions such as dissolution of molecular bonds, formation of oxygen free radicals, production of peroxidase, and denaturation of some protein structures. ${ }^{2}$ Finally, frequent washing and the use of medicaments and other topical substances alter the normal physiological skin balance in athletes, increasing the possibility for allergising substances to penetrate and therefore increasing the incidence of irritant contact dermatitis (ICD) or allergic contact dermatitis (ACD). The onset of ICD, especially after contact with solvents or other aggressive organic substances, may be aggravated by hyperhydrosis. ACD is elicited after contact and re-exposure to the same sensitising agent, with contributions from various other pathogenic cofactors. The presence of damage (abrasions, erosions, alterations in the hydrolipid mantle) predisposes the skin to sensitisation to any of these agents. ${ }^{3}$

The incidence of ACD was therefore assessed in a group of young people practising non-competitive sports. On the basis of the results obtained after patch tests to ascertain the sensitising agent involved in the skin disease, correlations were drawn between the allergens, the site of onset of the lesions, and the sport practised. The presence of a personal or family history of atopy was also taken into account.

\section{Materials and methods}

PATIENTS

Forty three young people (31 males and 12 females) with eczematous skin lesions suggesting ACD were studied. They had been reported to the Section for Allergic and Immunologic Diseases (SAIC) of Bari University by local sports institutions and clubs. All were students at the university or high school and were aged between 13 and 28 years (mean age 22). All had practiced non-competitive sports or physical activity for at least three years (range one to five years). The sports were fencing, running, sailing, football, swimming, cycling, subaqua diving, and fishing. As a control group, 38 students (20 males and 18 females) were studied from the same school who did not practise any sport (mean age 20 years). The following data were evaluated by the medical staff of SAIC: sex, age, sport practised, atopic status, family history of allergic disease, and symptoms. Skin lesions were examined and classified as erithematous, urticarioid, or erithematovescicular. The most common locations were hands, feet, and trunk. In about $80 \%$ of the subjects studied, by avoiding contact with specific equipment, it was 
possible to improve skin lesions and reduce complaints of itchiness, burning, etc (data not shown).

\section{PATCH TESTS}

The final diagnosis of ICD or ACD was made using the patch test. The haptens used were those included in the series drawn up by the Gruppo Italiano Ricerca Dermatiti da Contatto e Ambientali (Bracco, Milan, Italy). The patches were applied to skin on the back and were removed after 48 hours. Readings were made 10 minutes later, and the results were interpreted as true positive (allergic) or false positive (toxic) reactions according to the accepted guidelines for application and interpretation of the patch test. ${ }^{4}$ Additional readings at 72 hours were recorded in some doubtful cases to confirm or otherwise positive reactions seen after 48 hours. To assess the photopatch tests, the patches were removed after 24 hours and the underlying skin was subjected to a dose of UV rays. Readings were made after a further 24 hours. ${ }^{5}$

RADIOALLERGOABSORBENT TEST (RAST)

RAST to latex was evaluated according to the manufacturer's instructions as well as the CAP system (Pharmacia, Uppsala, Sweden). The skin prick test with a commercial extract of natural rubber latex was not performed for safety reasons; severe anaphylactic reactions to the latex skin prick test have been reported. ${ }^{6}$

Results

Of the 43 subjects studied, only eight had negative results after the patches were removed, despite having skin lesions; two of these were found to have lichenoid dermatitis and one psoriasis, while ICD was diagnosed in the other five (data not shown). Latex RAST positivity was observed in two patients who tested positive to thiourams (data not shown). Table 1 shows the patch test results. The highest number of positive cases was registered for thiourams and mercaptobenzothiazole. Nickel was in third place in our case series, followed by benzocaine and latex. Only one positive result was obtained for each of the remaining haptens. Three patients reacted positively to two haptens. In the control group, only two students had a positive result with nickel sulphate. None showed RAST positivity to latex.

Table 2 shows the sports practised and correlation with lesion sites and the prevalent responsible allergens. Finally, in table 3 the clinical features of the athletes studied are shown: mean age, sex, allergic symptoms, and family history of atopy. By examining clinical symptoms, we found an appreciable prevalence of cutaneous manifestations compared with other allergic symptoms, because of the close contact of particular equipment used during sporting activities. In the control group (students not practising a sport), we found that there was even a family history in 11 cases, and eight subjects were affected by allergic symptoms; only two had a positive reaction after the patches were removed.
Table 1 Positive patch test results

\begin{tabular}{llr}
\hline Haptens & Students practising sport & $\%$ \\
\hline Thiourams & 10 & 23.3 \\
Mercaptobenzothiazole & 9 & 20.9 \\
Nickel & 6 & 13.9 \\
Benzocaine & 4 & 9.3 \\
Epoxy resins & 1 & 2.3 \\
Potassium dichromate & 1 & 2.3 \\
Fragrance mix & 1 & 2.3 \\
Yellow 3 dispersion & 1 & 2.3 \\
Paraphenyldiamine & 1 & 2.3 \\
Colophony & 1 & 2.3 \\
Lanolin & 1 & 2.3 \\
Negative results & 8 & 18.6 \\
& Students not practising sport & \\
Nickel & 2 & 5.3
\end{tabular}

Table 2 Prevalence of allergens in the various sports activities

\begin{tabular}{|c|c|c|}
\hline & Hapten & Lesion site \\
\hline Cycling & $\begin{array}{l}\text { Benzocaine } \\
\text { Paraphenyldiamine } \\
\text { Potassium dichromate } \\
\text { Yellow } 3 \text { dispersion }\end{array}$ & $\begin{array}{l}\text { Trunk } \\
\text { Legs } \\
\text { Hands }\end{array}$ \\
\hline Sub & $\begin{array}{l}\text { Thiourams } \\
\text { Mercaptobenzothiazole } \\
\text { Nickel }\end{array}$ & $\begin{array}{l}\text { Trunk } \\
\text { Face }\end{array}$ \\
\hline Sailing & $\begin{array}{l}\text { Thiourams } \\
\text { Nickel } \\
\text { Latex }\end{array}$ & $\begin{array}{l}\text { Neck } \\
\text { Wrist }\end{array}$ \\
\hline Swimming & $\begin{array}{l}\text { Thiourams } \\
\text { Mercaptobenzothiazole } \\
\text { Fragrance mix }\end{array}$ & Trunk \\
\hline Fishing & $\begin{array}{l}\text { Nickel } \\
\text { Mercaptobenzothiazole }\end{array}$ & Hands \\
\hline Football & $\begin{array}{l}\text { Nickel } \\
\text { Benzocaine } \\
\text { Epoxy resin }\end{array}$ & $\begin{array}{l}\text { Hands } \\
\text { Feet }\end{array}$ \\
\hline Running & $\begin{array}{l}\text { Benzocaine } \\
\text { Lanolin }\end{array}$ & Feet \\
\hline Fencing & Colophony & $\begin{array}{l}\text { Hands } \\
\text { Trunk } \\
\text { Face }\end{array}$ \\
\hline
\end{tabular}

Table 3 Clinical features of the students studied

\begin{tabular}{lll}
\hline & $\begin{array}{l}\text { Students } \\
\text { practising sport } \\
(n=43)\end{array}$ & $\begin{array}{l}\text { Students not } \\
\text { practising sport } \\
(n=38)\end{array}$ \\
\hline Mean age (years) & 22 & 20 \\
Male & 31 & 20 \\
Female & 12 & 18 \\
Allergic symptoms & & \\
$\quad$ Eczema & 43 & 4 \\
$\quad$ Urticaria & 6 & 3 \\
Angioedema & 0 & 0 \\
Rhinitis & 2 & 1 \\
Asthma & 1 & 0 \\
$\quad$ Anaphylaxis & 0 & 0 \\
Family history of atopy & 29 & 11 \\
\end{tabular}

\section{Discussion}

Some forms of ACD have recently been reported in athletes. Boehncke et al described ACD in a diver wearing a neoprene swimming suit. This was not the first report of ACD to thiourams caused by swimming suits, which had previously been observed by Adams. ${ }^{8}$ ACD to thiourea has also been reported; this was due to its derivatives being used in the rubber vulcanisation process. ${ }^{9}$ Sensitisation to thiourea is classified as photodermatitis, and exposure to sun favours its development. Our data show that the most common causes of sensitisation in athletes are the chemical substances used in rubber processing; they include thiourams and mercaptobenzothiazole. Thiourea compounds are used as accelerators in the rubber industry and are known to cause ACD and photocontact dermatitis, although there have only been a 
few studies of it, largely looking at subaqua masks, jogging shoes, swimming costumes, orthopaedic devices, and gloves. ${ }^{10}{ }^{11}$ In our case series, ACD caused by rubber additives was the most common complaint. If this were to be confirmed in other studies, it would imply that ACD caused by rubber additives is a "professional" disease in athletes. However, frequent sensitisation to topical medicaments, such as Colophony, local anaesthetics, antiseptic and anti-inflammatory products, detergents, perfumes, and deodorants, should also be considered.

Changes in normal skin physiology induced by sports activities, the use of topical medicaments, frequent washing, and exposure to atmospheric agents during open air activities all predispose to skin diseases. Some of these forms may have a photoallergic pathogenesis. The common photoallergens include phenothiazine, sulphamide, and some essences contained in sticking plasters. The four cases of ACD caused by benzocaine were observed in runners, footballers, and cyclists. These sportspeople often require massage with creams containing topical anaesthetics. The site of the lesion is usually the trunk in subaqua divers and cyclists, the palms of the hands in cyclists, and the face in fencers and subaqua divers, all sites that often come into contact with the haptens responsible. If the allergens responsible for the sensitisation can be identified, the irritants can be avoided and the ACD prevented. Our data suggest that, to avoid the need for prolonged suspension of sports activities, it is wise to limit the use of topical drugs and aggressive agents and to avoid contact with topical photoallergens. Furthermore, skin is a site where lymphokines can be activated, resulting in expression of adhesion proteins, further cellular alterations, and greater release of local cytokines. ${ }^{12-14}$ As a consequence of the diminishing of the skin barrier, the allergen presenting cells can be reached more easily by the haptens.

The two cases of lichenoid dermatitis are reminiscent of a previous observation ${ }^{15}$ of this form of dermatitis in three professional football players, in which a photoallergic response to unidentified photoactive substances was hypothesised to be the cause. In contrast, the two students studied here did not show positive reactions to either the patch tests or the photo patch tests.

In conclusion, in this study the incidence of ACD was evaluated in a population of students, as a contribution to the systematic epidemiological study of ACD in people practising various sports. A more detailed evaluation is necessary of the various categories of athletes, in particular professional athletes, to assess the incidence of $\mathrm{ACD}$ and the frequency of the allergens, in relation also to the clothing and materials that particular athletes come into contact with during the course of sports activities.

The authors gratefully acknowledge the assistance of Dr Helena Kirk in the preparation of the English translation.

1 Levine N. Dermatologic aspect of sports medicine. $\mathcal{f} \mathrm{Am}$ Acad Dermatol 1980;5:415.

2 Suominen H, Heikkinen E, Moisio H, et al. Physical and chemical properties of skin in habitually trained and sedentary men. Br f Dermatol 1978;98:147.

3 Grebe W. Contact allergy and sport. Arb Paul Ehrlich Inst Georg Speyer Haus Ferdinand Blum Inst Frankf 1985;79:259.

4 Fisher AA (ed). Contact dermatitis. 4th ed. Philadelphia: Lea and Febiger, 1994

5 Hjorth N, Fregert S. Contact dermatitis. In: Rook A, Wilkinson DS, Ebling FJG, eds. Textbook of dermatology. Oxford, Edinburgh: Blackwell Scientific Publications, 1979

6 Kelly KJ, Kurup V, Zacharisen M, et al. Skin and serological testing in the diagnosis of latex allergy. $\mathcal{F}$ Allergy Clin Immunol 1993;91:1140-5.

7 Boehncke WH, Wessmann D, Zollner TM, et al. Allergic contact dermatitis from diphenylthiourea in a wet suit. Contact Dermatitis 1997;36:271.

8 Adams RM. Contact allergic dermatitis due to diethylthiourea in a wet suit. Contact Dermatitis 1982;8:277-8.

9 Dooms-Goossens A, Chrispeels MT, De Veylder H, et al. Contact and photocontact sensivity problems associated with thiourea and its derivatives: a review of the literature and case reports. Br f Dermatol 1987;116:573-9.

10 Canarasa JG, Romaguera C, Conde-Salazar L, et al. Thiourea reactivity in Spain. Contact Dermatitis 1985;12:220.

11 Heese A, Von Hintzenstern J, Peters KP, et al. Allergic and irritant reactions to rubber gloves in medical health services. Spectrum, diagnostic approach, and therapy. $\mathcal{F} \mathrm{Am}$ Acad Dermatol 1991;25:831-9.

12 Sharp NCC, Koutedakis Y. Sport and the overtraining syndrome: immunological aspects. Br Med Bull 1992;48: 518-33.

13 Ferry A, Picard F, Weill B, et al. Changes in leukocyte population induced by acute maximal and chronic submaximal exercise. Eur 7 Appl Physiol 1990;59:435-42.

14 Novak N, Bieber T. The skin as a target for allergic diseases. Allergy 2000;55:103-7.

15 Balabanova M, Kasandgieva J, Popov Y. Lichenoid dermatitis in 3 professional footballers. Contact Dermatitis 1993;28: $166-8$.

Take home message

Sports activity can cause changes to the skin barrier, resulting in allergic or irritant contact dermatitis from prevalent sensitivity to rubber. Further studies are needed to confirm the hypothesis of "professional" dermatitis from rubber in athletes. 